\title{
ORIGINAL RESEARCH \\ CT Analysis Demonstrates That Cochlear Height Does Not Change with Age
}

\author{
M.C. Mori \\ K.W. Chang
}

BACKGROUND AND PURPOSE: CH measurements can often be useful in the diagnosis of inner ear malformations associated with SNHL. Our aim was to establish the relationship between $\mathrm{CH}$ and age by using analysis of CT images in patients who underwent coronal CT scans of the temporal bone between 2001 and 2007.

\begin{abstract}
MATERIALS AND METHODS: We measured CH on coronal CT scans of the temporal bone of 422 ears scanned from 2001 to 2007 in 211 patients, 1 month to 23 years of age. Using multivariate linear regression analysis, we determined the relationship of $\mathrm{CH}$ to age, sex, and $\mathrm{HL}$ type. In addition, 11 patients with multiple scans at different ages were assessed for change in $\mathrm{CH}$ with age.
\end{abstract}

RESULTS: Average $\mathrm{CH}$ was $5.3 \mathrm{~mm}$ (normal range, 4.4-6.2 mm). Analysis showed no statistically significant change in $\mathrm{CH}$ across ages from 1 month to 23 years $(95 \% \mathrm{Cl}$ for regression line slope $=$ $-0.003,0.013)$. Likewise, there were no statistically significant differences in $\mathrm{CH}$ for patients with multiple scans at different ages. ICW increased with age as expected with increased cranial size. A small difference in $\mathrm{CH}$ between sexes was noted with males having greater $\mathrm{CH}$ s than females $(P<$ .01). All patients with hypoplastic cochleas, defined by a $\mathrm{CH}<2$ SDs from the mean $(4.48 \mathrm{~mm}$ for males and $4.25 \mathrm{~mm}$ for females), had HL with a positive predictive value of $86 \%$.

ConcLusions: $\mathrm{CH}$ does not change from 1 month of age to adulthood and is slightly greater in males than in females.

ABBREVIATIONS: $\mathrm{CH}=$ cochlear height; $\mathrm{CHL}=$ conductive hearing loss; $\mathrm{Cl}=$ confidence interval; $\mathrm{HL}=$ hearing loss; ICW = intercochlear width; $\mathrm{SNHL}=$ sensorineural hearing loss
$\mathbf{C}_{8}^{\circ}$ ochlear malformations are well-established causes of congenital SNHL in children. Cochlear anomalies such as common cavity deformity, cochlear aplasia, cochlear hypoplasia, and incomplete partition (classic Mondini deformity) are thought to result from the premature arrest in cochlear development during various stages of gestation. These abnormal cochleas have fewer than the standard 2.5-2.75 cochlear turns and diminished cochlear size. ${ }^{1}$ Recent studies have sought to increase the number of radiographically recognizable causes of congenital SNHL, because historically only $20 \%-39 \%$ of children with congenital SNHL have an associated radiographic abnormality. ${ }^{2-4} \mathrm{~A}$ study by Purcell et $\mathrm{al}^{5}$ found that measuring the $\mathrm{CH}$ resulted in the identification of twice as many cases of cochlear hypoplasia associated with SNHL as with visual inspection alone. ${ }^{6}$ While there are normative values for $\mathrm{CH}$, these values have not been differentiated by age or sex.

Previous studies have examined fetal and postnatal cochlear growth and have shown that the cochlea ceases growth and undergoes ossification between gestational weeks 16 and $25 .^{7-9}$ However, these studies are limited by small sample sizes and age ranges. There has never been a

Received November 5, 2010; accepted after revision May 1, 2011.

From the Department of Otolaryngology-Head and Neck Surgery, Stanford University School of Medicine, Palo Alto, California.

Matthew Mori was supported by a Stanford Medical Scholars Research Fellowship. All research was completed at Lucile Packard Children's Hospital, Stanford, California.

Please address correspondence to Kay W. Chang, MD, Department of OtolaryngologyHead and Neck Surgery, Stanford University, 801 Welch Rd, Palo Alto, CA 94305; e-mail: kchang@ohns.stanford.edu

http://dx.doi.org/10.3174/ajnr.A2713 comprehensive radiologic study of $\mathrm{CH}$ with age from shortly after birth to adulthood in living patients with large sample size, to our knowledge. Clinically, it is important to establish norms for $\mathrm{CH}$ for specific ages and sex to facilitate diagnosis of cochlear hypoplasia and other congenital malformations of the cochlea. Finding specific anatomic anomalies associated with HL can help direct treatment-for example, in surgical planning for patients receiving cochlear implants and research into the developmental causes of congenital HL.

\section{Materials and Methods}

This study was reviewed and approved by the Stanford University institutional review board.

\section{Patient Population}

This study included 211 patients (123 male, 88 female) with 396 ears undergoing temporal bone CT from 2001 to 2007 at Lucile Packard Children's Hospital, Stanford, California. Eleven patients had multiple temporal bone $\mathrm{CT}$ studies, with an average time of 2.6 years, maximum time of 5.5 years, and minimum time of 0.8 years between scans. Patients ranged from 1 month to 23 years of age, with an average age of 7.3 years age. Divided into quartiles by age, the patients in the first quartile had an age range of 0.1-3.1 years, the second quartile had an age range of 3.1-6.4 years, the third quartile had an age range of 6.4-10.6 years, and fourth quartile had an age range of 10.6-23.4 years. Patients underwent temporal bone $\mathrm{CT}$ as part of their routine radiologic evaluation for diagnoses, including, but not limited to, normal hearing with otologic symptoms, SNHL, CHL, mixed HL, cholesteatoma, otalgia, and external ear deformities. Patients with temporal bone $\mathrm{CT}$ scans were included regardless of hearing status or specific indications for radiologic examinations. 


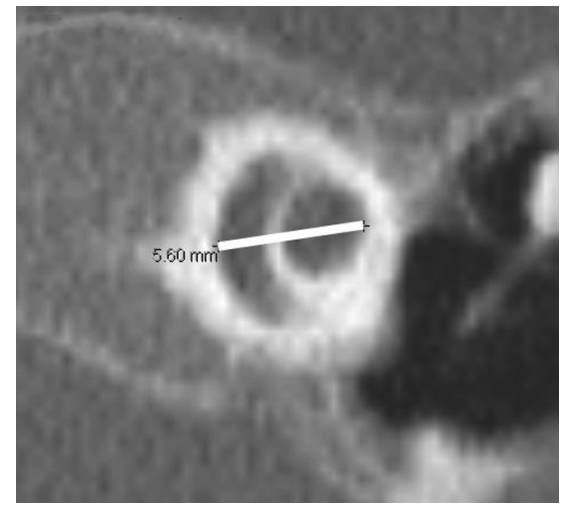

Fig 1. Cochlear height measured from the midpoint of the basal turn to the midpoint of the apical turn on a coronal section.

\section{CT of the Temporal Bone}

All studies were performed at the Lucile Packard Children's Hospital by using standard temporal bone protocol. Contiguous 1-mm scans of the temporal bone were acquired in the axial and coronal plane with a Somatom Sensation 64-detector row system (Siemens, Malvern, Pennsylvania). Studies were reviewed by using PACS with magnification and electronic caliper capabilities.

\section{CH Measurements}

Measurements were taken by a single reader by using electronic calipers and recorded in units of millimeters at a magnification of 4 , center of 200, and width of 4000 . CH was defined as the measurement from the midpoint of the basal turn to the midpoint of the apical turn taken perpendicular to the axes of the cochlear lumens in the coronal view (Fig 1)..$^{5}$ It was measured on the cut with the maximum height that included the basal and apical turns. The distance between the left and right cochlea (ICW) was also measured in each scan.

\section{Statistics}

We used Excel (Microsoft, Redmond, Washington) to record and analyze our data. Normative values were determined by using 74 normal-hearing ears, 52 from male patients and 22 from female patients. We calculated averages and SDs. $\mathrm{CH}$ was considered normal if it was within 2 SDs of the sex-specific normative mean $\mathrm{CH}$. Two-sample $t$ test statistical analysis was used to compare $\mathrm{CHs}$ of normal-hearing patients with the CHs of SNHL, CHL, mixed HL, and unknownhearing status in patients grouped by hearing status and sex. For the relationships among $\mathrm{CH}$ and sex and age, we used multivariate linear regression analysis.

\section{Audiometry}

Audiology data acquired by the audiologists at Lucile Packard Children's Hospital was used to classify patients' hearing into 5 categories. On the basis of the audiology results, we recorded a classification of normal hearing, SNHL, CHL, or mixed HL for each ear. Patients who did not have audiology tests were classified as having "unknown" hearing.

\section{Results}

\section{Patient Population}

A total of 211 patients (422 ears) was included in this study. This included 162 ears with SNHL, 101 ears with CHL, 25 ears

\begin{tabular}{lcccccc}
\hline \multicolumn{7}{l}{ Table 1: Results of CT studies of $\mathbf{C H}^{\mathbf{a}}$} \\
\hline Hearing & & & & & \\
Category & No. of Ears & Min. & Max. & Mean & SD & $P$ Value \\
\hline SNHL (all) & 162 & 2.5 & 6.1 & 5.23 & 0.46 & $.002^{\mathrm{b}}$ \\
Males & 90 & 4.0 & 6.1 & 5.29 & 0.37 & $.004^{\mathrm{b}}$ \\
Females & 72 & 2.5 & 6.1 & 5.16 & 0.55 & .33 \\
CHL (all) & 101 & 4.2 & 6.1 & 5.32 & 0.37 & .09 \\
Males & 61 & 4.2 & 6.1 & 5.38 & 0.39 & .17 \\
Females & 40 & 4.7 & 6.1 & 5.24 & 0.33 & .60 \\
Mixed HL (all) & 25 & 3.4 & 5.5 & 4.67 & 0.69 & $<.00001^{\text {b }}$ \\
Males & 11 & 3.4 & 5.5 & 4.53 & 0.69 & $<.00001^{\text {b }}$ \\
Females & 14 & 3.5 & 5.4 & 4.79 & 0.70 & $.008^{\mathrm{b}}$ \\
Normal (all) & 74 & 4.5 & 6.3 & 5.42 & 0.38 & 1 \\
Males & 52 & 4.5 & 6.3 & 5.48 & 0.38 & 1 \\
Females & 22 & 4.6 & 6.0 & 5.28 & 0.35 & 1 \\
Unknown (all) & 60 & 4.6 & 5.9 & 5.29 & 0.30 & .04 \\
Males & 32 & 4.6 & 5.9 & 5.32 & 0.35 & .06 \\
Females & 28 & 4.6 & 5.6 & 5.26 & 0.26 & .82 \\
Total (all) & 422 & 2.5 & 6.3 & 5.26 & 0.45 & \\
Males & 246 & 3.4 & 6.3 & 5.32 & 0.43 & $.009^{\mathrm{c}}$ \\
Females & 176 & 2.5 & 6.1 & 5.18 & 0.47 & \\
\hline
\end{tabular}

Note:-Min. indicates minimum; Max, maximum.

${ }^{a}$ Two-sample $t$ test $P$ values are for comparisons among SNHL, CHL, mixed $\mathrm{HL}$, or unknown-hearing ears and normal-hearing ears divided by all, male, or female.

b Statistically significant differences $(P<.01)$.

${ }^{c}$ For the comparison of male and female $\mathrm{CHs}$, multivariate linear regression controlling for age and ICW was used.

with mixed HL, 74 ears with normal hearing, and 60 ears with unknown hearing.

\section{$C T$}

$\mathrm{CH}$ by Sex and HL Type. Results of the $\mathrm{CH}$ measurements are presented in Table 1. When we controlled for age and ICW, multivariate linear regression analysis showed a statistically significant difference between male and female $\mathrm{CH}$, with a regression coefficient of $0.12(P<.01)$. Female patients had an average $\mathrm{CH}$ of $5.2 \mathrm{~mm}$ ( $95 \% \mathrm{CI}, 4.3-6.1 \mathrm{~mm})$, while male patients had an average $\mathrm{CH}$ of $5.3 \mathrm{~mm}$ (95\% CI, 4.5-6.2 mm). Two-sample $t$ test also demonstrated a statistically significant difference between male and female $\mathrm{CH}$ for normal-hearing patients $(P<.05)$. Normal-hearing females had a mean $\mathrm{CH}$ of $5.3 \mathrm{~mm}$ (95\% CI, 4.6-6.0 mm) and normal-hearing males' mean $\mathrm{CH}$ was $5.5 \mathrm{~mm}$ (95\% CI, 4.7-6.2 mm). In the comparison of $\mathrm{HL}$ type and $\mathrm{CH}$, we noted that the mean $\mathrm{CH}$ s of ears with SNHL and mixed HL were significantly less than the mean $\mathrm{CH}$ s of ears with normal hearing. There was no statistical difference between left $\mathrm{CH}$ and right $\mathrm{CH}$.

$\mathrm{CH}$ versus Age. $\mathrm{CH}$ is plotted versus age in Fig 2. The regression line equation for the relationship between $\mathrm{CH}$ and age for all categories of hearing is $\mathrm{CH}=0.005$ [Age] +5.22 . The regression coefficient was not statistically significant (95\% CI, 0.003-0.013). Even when regression coefficients were calculated dividing the population by hearing category, the 95\% CI always included zero, again demonstrating that $\mathrm{CH}$ was not affected by age. Using the 2 -sample $t$ test, we also compared the $\mathrm{CHs}$ of patients divided into quartiles by age with no statistical difference between the groups. Most significantly, the $\mathrm{CHs}$ of the first quartile (ages, $0.1-3.1$ years) were not statistically different from those of the fourth quartile (ages, 10.6-23.4 years).

$\mathrm{CH}$ versus ICW. In contrast to the lack of change in $\mathrm{CH}$ growth, ICW increased logarithmically with age (equation: $\mathrm{ICW}=5.7 \mathrm{Ln}[$ Age $]+40$ ) as seen in Fig 3. Using multivariate 


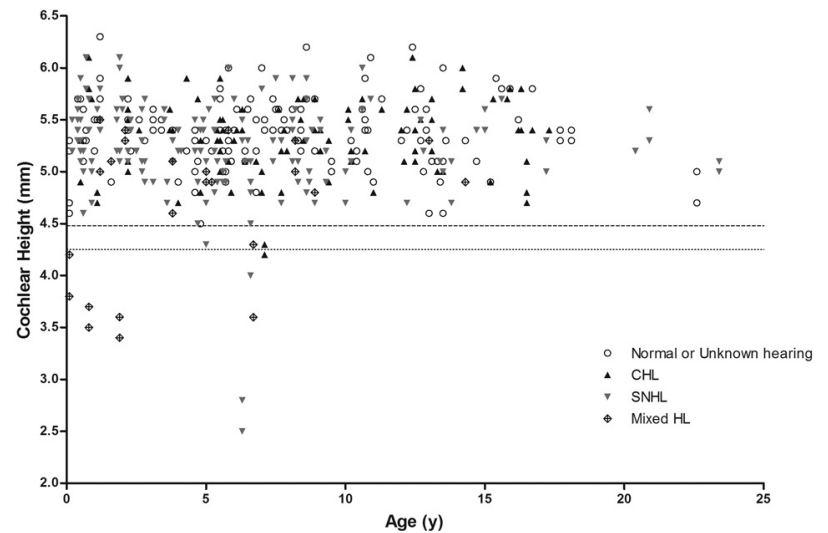

Fig 2. $\mathrm{CH}$ versus age categorized by patient hearing category. The upper dashed line (4.48 $\mathrm{mm})$ is $2 \mathrm{SDs}$ below the male mean $\mathrm{CH}$. The lower dashed line $(4.25 \mathrm{~mm})$ is 2 SDs below female mean $\mathrm{CH}$.

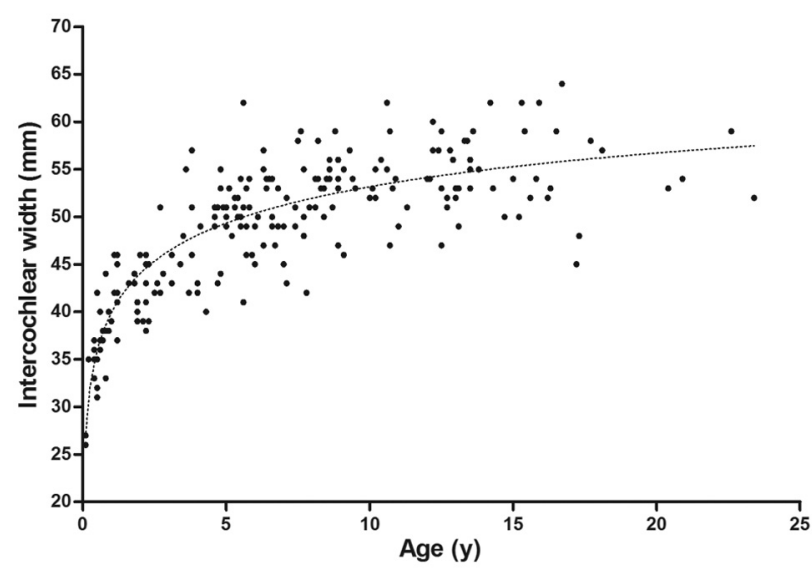

Fig 3. ICW versus age for all patients.



Fig 4. $\mathrm{CH}$ versus age and ICW versus age for patients with multiple imaging studies. Each set of data points connected by a line represents a single patient's left $\mathrm{CH}$, right $\mathrm{CH}$, or ICW.

linear regression controlling for age and sex, we found ICW to have no statistically significant relationship with $\mathrm{CH}(95 \% \mathrm{CI}$, -0.005-0.013), indicating that $\mathrm{CH}$ was not affected by skull size.

Patients with Multiple Imaging Studies at Different Time Points. Results are plotted in Fig 4. Logarithmic growth is evident in the plot of ICW versus age, while $\mathrm{CH}$ does not change significantly with age. The mean slope of the lines connecting individual patient's $\mathrm{CH}$ data points is -0.03 (95\% CI,
-0.11-0.04), demonstrating no significant changes in $\mathrm{CH}$ with age. The mean slope of the lines connecting individual patient's ICW data points is 1.13 (95\% CI, 0.50-1.75), demonstrating statistically significant changes in ICW with age.

Patients with Small CHs. All patients with hypoplastic cochleas, defined by a $\mathrm{CH}<2$ SDs from the calculated normalhearing $\mathrm{CH}$ mean, $<4.48 \mathrm{~mm}$ for males and $4.25 \mathrm{~mm}$ for females, had either SNHL, CHL, or mixed HL. Two of the patients had branchio-oto-renal syndrome, 2 patients had CHARGE syndrome, 1 patient had bilateral vestibulocochlear dysplasia with a unilateral Mondini malformation, 1 patient had enlarged vestibular aqueduct syndrome, and 1 patient had bilateral class II microtia with external auditory canal atresia.

\section{Discussion}

In this study, we examined the relationship between postnatal cochlear size and age. The human cochlea has long been thought to cease growing before birth. In the third week of gestation, the cochlea initially begins as the otic placode, an ectodermal thickening that develops into the whole inner ear. By the eighth to ninth week of gestation, the cochlea has grown and completed its coiling into 2.5-2.75 turns. ${ }^{1,10}$ However, after the first trimester, it has been difficult to assess the exact timing of the end of cochlear growth and development due to lack of fetal specimens. ${ }^{10}$ Before imaging was widely available, the complete maturation of the cochlea without further growth was thought to be true largely because ossification of the otic capsule is complete by approximately $20-25$ weeks gestation. $^{11}$

More recent studies have analyzed images of small sample sizes of fetal museum specimens to estimate cochlear growth cessation. A study published in 2004 by Jeffery and Spoor ${ }^{8}$ by using high-resolution MR imaging of 41 late first trimester to early third trimester fetal museum specimens from the early to mid-20th century showed that the height and width of the basal turn of the cochlea reaches adult equivalent size by $16-19$ weeks gestation. Another study by Nemzek et $\mathrm{al}^{9}$ by using 18 fetal specimens and CT or MR imaging found that the length of the basal turn of the cochlea and the otic capsule of the fetus reached adult dimensions by approximately 21 weeks' gestation. Postnatal growth of the cochlea has been measured in even fewer studies. One postmortem study of 27 children from 12 hours to 12 years of age by Eby and $\mathrm{Nadol}^{7}$ showed no significant changes in $\mathrm{CH}$ or width with age. Our study used a greater number of patients with a broader age range than previous studies. By showing no statistically significant change in $\mathrm{CH}$ with age, our data significantly strengthen the existing belief that the cochlea does not grow postnatally.

Although $\mathrm{CH}$ does not change with age, average $\mathrm{CH}$ varies with hearing status and sex. Patients with SNHL and mixed HL demonstrate significantly smaller $\mathrm{CH}$ s compared with normal-hearing patients. While cochlear hypoplasia alone is associated with SNHL, it is only one of the malformations resulting from arrested or aberrant development of the inner ear at various stages of embryogenesis. ${ }^{1}$ Some of these other congenital abnormalities, such as dilated vestibular aqueduct, can coexist with cochlear hypoplasia and are independently associated with SNHL. The cochlear malformations seen in our patients with cochlear hypoplasia (Table 2) included aplastic modiolus, hypoplastic modiolus, Mondini deformity, 


\begin{tabular}{|c|c|c|c|c|c|c|}
\hline Patient & $\begin{array}{l}\text { Age (yr) } \\
\text { Sex }\end{array}$ & $\begin{array}{l}\mathrm{LCH} \\
(\mathrm{mm})\end{array}$ & $\begin{array}{l}\mathrm{R} \mathrm{CH} \\
(\mathrm{mm})\end{array}$ & TYPE HL & Diagnosis & CT Findings \\
\hline 1 & $\begin{array}{l}6.3 \\
\text { Female }\end{array}$ & 2.8 & 2.5 & $\begin{array}{l}\text { SNHL, } \\
\quad \text { bilaterally }\end{array}$ & $\begin{array}{l}\text { Bilateral vestibulocochlear dysplasia, } \\
\text { L Mondini malformation }\end{array}$ & $\begin{array}{l}\text { Bilateral vestibulocochlear dysplasia } \\
\text { R common chamber malformation, absent vestibular } \\
\text { aqueduct, aplastic modiolus } \\
\text { L Mondini malformation (hypoplastic cochlea with } \\
\text { partition defect) }\end{array}$ \\
\hline 2 & $\begin{array}{l}1.9 \\
\text { Male }\end{array}$ & 3.4 & 3.6 & Mixed HL & BOR syndrome & $\begin{array}{l}\text { Bilateral dilated vestibular aqueduct with small } \\
\text { modiolus, trumpet-shaped IAC, small mass in R } \\
\text { middle ear (possible congenital cholesteatoma) }\end{array}$ \\
\hline 3 & $\begin{array}{l}0.8 \\
\text { Female }\end{array}$ & 3.7 & 3.5 & Mixed HL & BOR syndrome & $\begin{array}{l}\text { Bilateral tympanostomy tubes, hypoplasia of modiolus, } \\
\text { vestibular ectasia, dilated vestibular aqueducts, } \\
\text { Mondini deformities (cochlear ectasia with partition } \\
\text { defects), question of ossicular fusion } \\
\text { R middle ear and mastoid air cell opacification; absent } \\
\text { vs hypoplastic stapes } \\
\text { L hypoplastic mastoid with soft tissue thickening at L } \\
\text { mesotympanum }\end{array}$ \\
\hline 4 & $\begin{array}{l}6.7 \\
\text { Female }\end{array}$ & 3.6 & 4.3 & $\begin{array}{l}\text { Mixed } \mathrm{HL}, \\
\quad \text { bilaterally }\end{array}$ & CHARGE syndrome & $\begin{array}{l}\text { Bilateral hypoplastic SCCs, prominent EAC, vestibular } \\
\text { dysplasia, cochlear ectasia with partition defects, } \\
\text { hypoplastic stapes } \\
\text { R sclerosis of ossicles, poorly visualized oval window, } \\
\text { L poorly defined modiolus }\end{array}$ \\
\hline 5 & $\begin{array}{l}0.1 \\
\text { Male }\end{array}$ & 4.2 & 3.8 & $\begin{array}{l}\text { Mixed } \mathrm{HL}, \\
\quad \text { bilaterally }\end{array}$ & CHARGE syndrome & $\begin{array}{l}\text { Bilateral absent SCCs, middle ear/mastoid air cell } \\
\text { congestion or inflammation, normal middle ear } \\
\text { morphology }\end{array}$ \\
\hline 6 & $\begin{array}{l}6.6 \\
\text { Male }\end{array}$ & 4.0 & 4.5 & $\begin{array}{l}\text { SNHL, } \\
\quad \text { bilaterally }\end{array}$ & EVA syndrome & $\begin{array}{l}\text { Bilateral enlarged vestibular aqueducts, R cochlear } \\
\text { implant, L hypoplastic modiolus }\end{array}$ \\
\hline 7 & $\begin{array}{l}7.1 \\
\text { Male }\end{array}$ & 4.2 & 4.3 & $\begin{array}{l}\mathrm{CHL}, \\
\quad \text { bilaterally }\end{array}$ & $\begin{array}{l}\text { Bilateral class II microtia and EAC } \\
\text { atresia }\end{array}$ & $\begin{array}{l}\text { R malformed IAC, partially formed middle ear cavity, } \\
\text { poorly defined ossicles, narrow EAC, normal SCCs/ } \\
\text { vestibule } \\
\text { L absent lateral SCC, vestibular dysplasia, ossicular } \\
\text { dysplasia, absent membranous EAC, normal cochlea }\end{array}$ \\
\hline
\end{tabular}

Note:- R indicates right; L, left; IAC, internal auditory canal; SCC, semicircular canals; BOR, branchio-oto-renal; EVA, enlarged vestibular aqueduct; EAC, external auditory canal.. ${ }^{\mathrm{a}} \mathrm{CHs}>2 \mathrm{SDs}$ below the mean $\mathrm{CH}$.

and vestibulocochlear dysplasia. Also there are many causes of mixed HL and SNHL that do not involve small cochleas. Thus, the sensitivity of cochlear hypoplasia in identifying patients with mixed HL or SNHL is low. Our data showed a sensitivity of $\sim 6 \%$. However, cochlear hypoplasia is a useful predictor of SNHL. Six of the 7 patients with cochlear hypoplasia had mixed HL or SNHL, giving cochlear hypoplasia a positive predictive value of $86 \%$ for an associated mixed HL or SNHL. Therefore, it is important to measure $\mathrm{CH}$ given the relatively low percentage of associated radiographic abnormalities identifiable with congenital HL. As found in previous studies, standard measurements of the cochlea can double the identification of cochlear hypoplasia as a congenital malformation associated with SNHL. ${ }^{5}$

We also found that $\mathrm{CH}$ differs between males and females. This difference is likely not functional but should be used in establishing sex-specific $\mathrm{CH}$ normative measurements to aid in the diagnosis of cochlear hypoplasia. In our study normal CHs were $5.2 \mathrm{~mm}$ (95\% CI, 4.3-6.1 mm) in females and 5.3 $\mathrm{mm}$ (95\% CI 4.5-6.2 mm) in males. Similar sexual dimorphism has been demonstrated in separate studies measuring cochlear length and the vestibular apparatus. ${ }^{12,13}$

Interscan variation was evidenced by our $\mathrm{CH}$ measurements of patients with multiple scans. Cochlear height measurements differed by as much as $0.7 \mathrm{~mm}$ among scans of the same ear. This variability could be due to differences in CT scan orientation or image quality.
There were several limitations to this study. There was only 1 reader. Multiple readers would increase the reliability and reproducibility of our data. CT scans were not uniformly aligned. This means that we measured the $\mathrm{CH}$ through slightly different cuts, depending on the orientation of the scan. Ideally, we would reformat each cochlea on the basis of anatomic landmarks to capture an anatomically standardized $\mathrm{CH}$. However, we chose our method without reformatting because it is more consistent with clinical practice and still offers a good estimate of $\mathrm{CH}$. Time between scans for patients with multiple scans was relatively short. Although we were able to assess significant changes in ICW, long intervals between scans are ideal for assessing $\mathrm{CH}$ changes, especially if the scans are obtained right after birth and once the patient reaches adulthood. Another limitation is that we did not have any patients who were younger than 1 month of age. Theoretically, the cochlea could grow in the month after birth. However, we think that this is unlikely, given the evidence of studies showing cochlear growth cessation in fetal specimens.

\section{Conclusions}

In conjunction with previous fetal specimen and postnatal postmortem studies, this radiologic study provides strong evidence that there is no cochlear growth postnatally. Although $\mathrm{CH}$ does not change from 1 month of age to early adulthood, $\mathrm{CH}$ does vary on the basis of sex, with males having slightly greater measurements than females. In addition, the average 
$\mathrm{CH}$ is smaller in patients with mixed HL or sensorineural HL than in patients with normal hearing. Normative sex-specific $\mathrm{CH}$ measurements can be used across all ages to diagnose cochlear hypoplasia. Using 2 SDs below the mean, we found that CHs below $4.48 \mathrm{~mm}$ in males and $4.25 \mathrm{~mm}$ in females were useful thresholds to define cochlear hypoplasia resulting in HL.

\section{References}

1. Jackler RK, Luxford WM, House WF. Congenital malformations of the inner ear: a classification based on embryogenesis. Laryngoscope 1987;97(3 pt 2 suppl 40):2-14

2. Jensen J. Malformations of the inner ear in deaf children: a tomographic and clinical study. Acta Radiol Diagn (Stockh) 1968(suppl 286):283+

3. Mafong DD, Shin EJ, Lalwani AK. Use of laboratory evaluation and radiologic imaging in the diagnostic evaluation of children with sensorineural hearing loss. Laryngoscope 2002;112:1-7

4. Chen JL, Gittleman A, Barnes PD, et al. Utility of temporal bone computed tomographic measurements in the evaluation of inner ear malformations. Arch Otolaryngol Head Neck Surg 2008;134:50-56
5. Purcell D, Johnson J, Fischbein N, et al. Establishment of normative cochlear and vestibular measurements to aid in the diagnosis of inner ear malformations. Otolaryngol Head Neck Surg 2003;128:78-87

6. Purcell DD, Fischbein NJ, Patel A, et al. Two temporal bone computed tomography measurements increase recognition of malformations and predict sensorineural hearing loss. Laryngoscope 2006;116:1439-46

7. Eby TL, Nadol JB Jr. Postnatal growth of the human temporal bone: implications for cochlear implants in children. Ann Otol Rhinol Laryngol 1986;95(4 pt 1):356-64

8. Jeffery N, Spoor F. Prenatal growth and development of the modern human labyrinth. J Anat 2004;204:71-92

9. Nemzek WR, Brodie HA, Chong BW, et al. Imaging findings of the developing temporal bone in fetal specimens. AJNR Am J Neuroradiol 1996;17:1467-77

10. Pujol R, Lavigne-Rebillard M, Uziel A. Development of the human cochlea. Acta Otolaryngol Suppl 1991;482:7-12, discussion 13

11. Bast T. Ossification of the otic capsule in human fetuses. Carnegie Contributions to Embryology 1930;121:53-82

12. Sato H, Sando I, Takahashi H. Sexual dimorphism and development of the human cochlea: computer 3-D measurement. Acta Otolaryngol 1991;111: 1037-40

13. Sato H, Sando I, Takahashi H. Computer-aided three-dimensional measurement of the human vestibular apparatus. Otolaryngol Head Neck Surg 1992; 107:405-09 